\title{
Increased motor vehicle crashes following the 2016 Kumamoto earthquake, Japan: an interrupted time series analysis of property damage crashes
}

\author{
Takuya Maruyama $^{1}$ (D) Kazutake Taguchi ${ }^{2}$
}

Received: 6 January 2021 / Accepted: 16 April 2021 / Published online: 28 April 2021

(c) The Author(s) 2021

\begin{abstract}
Driving after natural disasters entails a substantial amount of stress; therefore, the number of motor vehicle crashes may increase. However, few studies have examined this issue. This study investigated motor vehicle crashes after the 2016 Kumamoto earthquake in Japan. Monthly data about crashes resulting in property damage from 49 municipalities in Kumamoto from 2015 to 2018 were used. An interrupted time series analysis using Poisson or negative binomial regression models was conducted for 49 municipalities; the models were estimated for four classified areas to obtain the robust results. We found that property damage crashes increased significantly in the heavily affected area (Relative Risk $(\mathrm{RR})=1.48,95 \%$ Confidence interval $(\mathrm{CI}): 1.29,1.71)$ and the affected area $(\mathrm{RR}=1.25$, 95\% CI: 1.15, 1.36) after the earthquake. A mountainous area showed a reduction in property damage crashes despite its heavy damage $(\mathrm{RR}=0.74,95 \% \mathrm{CI}: 0.67,0.82)$, which can be attributed to the closure of its main gate routes. The unaffected area showed no difference before and after the earthquake. Geographical presentation of the result demonstrates a clear positive association of earthquake damage and increased crashes. The findings of this study highlight the importance of motor-vehicle-crash alerts after an earthquake.
\end{abstract}

Keywords Earthquake disaster - Motor vehicle crashes resulting in property damage . Time series count data model $\cdot$ Poisson regression model $\cdot$ Negative binomial regression model

\section{Introduction}

Natural disasters can change the activities in a society in various ways. They can lead to an abnormal increase in the travel demands of evacuees, rescue teams, and volunteers, roads can be damaged, traffic congestion can become more severe than in normal situations, and drivers

Takuya Maruyama

takumaru@kumamoto-u.ac.jp

1 Center for Water Resource, Marine Environment, and Disaster Management, Kumamoto

University, 2-39-1 Kurokami, Kumamoto 860-8555, Japan

2 Department of Civil Engineering, Kumamoto University, Kumamoto, Japan 
are forced to drive in stressful conditions (Iida et al. 2000; Nakagawa and Kobayashi 2006; Kawasaki et al. 2017; Casey et al. 2019). These factors can increase the number of motor vehicle crashes after a disaster.

Many studies have explored the impact of natural disasters on economic activities (Eckhardt et al. 2019; Yonson et al. 2020; Adeel et al. 2020; Chen and Chang 2020; Jiménez Martínez et al. 2020); however, few studies have examined its impact on motor vehicle crashes. Several researchers (Hino et al. 1996, 1997a; Wada et al. 1997) have reported an increase in motor vehicle crashes following the 1995 Great Hanshin-Awaji Earthquake in Japan. Hagita and Yokozeki (2019) summarized the increase in motor vehicle crashes due to earthquakes in the period 1995-2008 in Japan. A report (TMNRC 2016) described the increase in motor vehicle crashes by the 2011 Great East Japan Earthquake. However, the statistical analysis of these studies can be extended considering the time series nature of motor-vehicle-crash data. In this study, we investigated motor vehicle crashes following the 2016 Kumamoto earthquake in Japan using interrupted time series (ITS) analysis. ITS analysis is considered to be the most robust quasi-experimental methodology to evaluate the longitudinal effect of unexpected events (Lopez Bernal et al. 2017); however, its application to motor-vehicle-crash analysis after an earthquake is limited (Casey et al. 2019).

After the 2016 Kumamoto earthquake, many evacuees stayed overnight in their cars (Araki et al. 2017; Inazuki 2018). Consequently, their driving will be impaired because of fatigue. Although this could be a new factor that increases motor vehicle crashes, the investigation of the Kumamoto earthquake is insufficient. Taguchi et al. (2019a, b) investigated this issue, but their analysis was preliminary. This study extends their analysis and comprehensively examines the change in motor vehicle crashes caused by the Kumamoto earthquake using ITS.

This study examines the following hypotheses: Factors that are likely to increase the probability of a motor vehicle crash, such as driver stress, increase after an earthquake, especially in the affected area near the epicenter where there is heavy damage to housing; consequently, the increase in crashes is higher there. The number of crashes increases to a very high level in the period immediately after the earthquake; it returns to its normal level after some time interval (the 'impact period'), which also varies geographically with the level of damage. We examine these hypotheses using monthly crash data for each of the 49 municipalities in Kumamoto Prefecture from 2015 to 2018. In sum, the objectives of this study are to determine the change in the number of motor vehicle crashes for each municipality caused by the Kumamoto earthquake using ITS; to compare this change with the housing damage; to classify the municipalities into four areas by property damage and crash rate; and to demonstrate robustly the change in crashes and impact periods across these areas.

We found that motor vehicle crashes resulting in property damage (property damage crashes) increased in the affected areas after the earthquake. This paper demonstrates a clear statistical association between earthquake damage and increase in crashes using ITS.

The rest of this paper is organized as follows: Sect. 2 presents a review of the related literature; Sect. 3 presents the data used in this study; Sect. 4 explains the method used; Sect. 5 presents the results of this study; Sect. 6 discusses the obtained results; and Sect. 7 summarizes the main findings of the study. 


\section{Literature review}

This section summarizes the reports and findings of actual motor vehicle crashes after the occurrence of disasters. We begin with case studies after earthquakes and then those of man-made disasters. We also reviewed the time series analysis of the impact of earthquakes and examined how the analysis can be applied to our study. Finally, we identified research gaps and highlighted the original contributions of our study.

\subsection{Case studies after natural earthquakes}

Several researchers have analyzed motor vehicle crashes that occurred after the 1995 Great Hanshin-Awaji Earthquake in Japan. Hino et al. (1996, 1997a) showed that the number of crashes resulting in injury or death (injury crashes) in Hyogo prefecture increased by an average of $10 \%$ compared with that of the previous year before the earthquake occurred. Motor vehicle crashes also increased over a long period, not only in severely damaged municipalities but also in municipalities with minor damage. Wada et al. (1997) investigated road traffic management after disasters following increased crash problems. Ueno et al (1997) and Hino et al. (1997b) examined how companies and individuals handled the challenges of road traffic after the earthquake, using a questionnaire survey. Their study revealed that although individuals understood traffic regulations, drivers appeared to break these rules, resulting in an increased number of motor vehicle crashes. Following the earthquake, many researchers have investigated transportation issues during disasters and discussed the importance of road network development and traffic management systems in disasters (Taniguchi 1997; Iida et al. 2000; Nakagawa and Kobayashi 2006).

TMNRC (2016) examined motor vehicle crashes after the 2011 Great East Japan Earthquake and reported that, in some severely damaged municipalities in Miyagi, injury crashes decreased and property damage crashes increased. The above report also revealed changes in locations with frequent property damage crashes after the disaster. Hagita and Yokozeki (2019) analyzed the number of motor vehicle crashes during major earthquakes in Japan from 1995 to 2008 and found that injury crashes generally increased in areas with high population densities.

Helton and Head (2012) compared the response task of participants before and after the 2010 Christchurch earthquake in New Zealand. Their results indicate that natural disasters may adversely affect driving performance. Some studies have focused on driving behavior during an earthquake using a questionnaire survey and a driving simulator (Jibiki et al. 2015; Kiyono et al. 2017; Matsumoto et al. 2018). These studies did not investigate actual motor vehicle crashes; however, they suggested possible changes in driving behavior during an earthquake.

\subsection{Case studies after terror attacks}

Some studies have analyzed motor vehicle crashes after terrorist attacks. Su et al. (2009) reported an increase in motor-vehicle-crash fatalities around the area where the September 11 terrorist attacks were carried out in the U.S. Gigerenzer (2004) hypothesized that the increase in fatalities was due to changes in travel mode and analyzed the relationship between traffic fatalities and changes in mode choice. The author demonstrated that people tended to avoid airplanes after terrorist attacks and inferred that drivers' driving quality deteriorated due to driving fatigue resulting from increased long-distance driving, leading 
to increased motor vehicle crashes. In the case of terrorism in Israel, severe crashes with casualties frequently occurred three days after terrorist attacks, and motor-vehicle-crash fatalities increased by approximately $35 \%$ from the month before the attacks (Stecklov and Goldstein 2004). These results indicate that terrorist attacks can adversely affect the mental and physical conditions of drivers and lead to an increase in motor vehicle crashes. In other words, driving quality may decrease after terrorist attacks.

\subsection{Interrupted time series analysis for impact evaluation}

ITS analysis is a valuable tool for evaluating policy interventions and events and has been used in various research fields (Jandoc et al. 2015; Lopez Bernal et al. 2017; Turner et al. 2020). Many studies used ITS analysis to investigate the impact of disasters in several research fields. Such studies include the impact of earthquake and nuclear disaster on birth rate (Kurita 2019), impact of flood on infectious diseases (Zhang et al. 2019), impact of technological disasters (chlorine spill) on primary care access (Runkle et al. 2012), increase in suicide trends following an earthquake (Yang et al. 2005), impact of natural disasters on capital markets (Worthington and Valadkhani 2004), increase in suicide rates following terrorist attacks (Pridemore et al. 2009), impact of flooding on mental health (Milojevic et al. 2017), and decrease in the number of tourists in disaster-affected areas (Nishimura et al. 2012). In a case study of the 2016 Kumamoto earthquake, Matsushita (2019) examined the impact of a special subsidy system for tourists in the affected area using ITS.

The use of ITS in motor-vehicle-crash analysis includes the effect of high fuel price (Naqvi et al. 2020), ban on cellphone use (Liu et al. 2019), the effect of $20 \mathrm{mph}$ traffic speed zones on crashes (Grundy et al. 2009), and the effect of change in street lightning on crashes and crimes (Steinbach et al. 2015). Lavrenz et al. (2018) reviewed time series modeling in traffic safety research. Although many studies have been conducted on motor vehicle crashes using ITS, including those mentioned above, limited studies have examined the impact of earthquake on motor vehicle crashes using ITS. Recently, Casey et al. (2019) demonstrated an increase in motor vehicle crashes following the earthquakes induced by wastewater injection. They reported a $4.6 \%$ increase in motor vehicle crashes in the high exposure counties in the month following the earthquakes of magnitude 4 or greater, using time series model.

\subsection{Current study}

Although several studies have investigated the impact of earthquakes on motor vehicle crashes, the evidence is insufficient to generalize the effect for policymaking. Therefore, this study used the 2016 Kumamoto earthquake as a case study and actual motor-vehiclecrash data. The purpose of this study is to determine the actual distribution of motor vehicle crashes after the Kumamoto earthquake and to analyze changes in crash rates caused by the earthquake. None of the existing studies on the impact of natural earthquakes on motor vehicle crashes (Hino et al. 1996, 1997a) used ITS; the present study provides statistical findings using time series data. Furthermore, while Casey et al. (2019) conducted analyses on human-induced earthquakes with slight earthquake damage, we focused on the natural earthquakes that result in heavy building damage and loss of human lives. In addition, we explored the length of the impact of earthquakes on motor vehicle crashes, which were not investigated by Casey et al. (2019). 


\section{Data}

Two great earthquakes with magnitudes of 6.5 and 7.3 hit Kumamoto, Japan on April 14 and 16, 2016. The earthquakes caused strong shaking with a seismic intensity of 7 in Mashiki and Nishihara. Over 4,000 aftershocks with seismic intensities of 1 or more occurred within six months of the first tremor (JMA 2018). The tremors caused over 270 direct and indirect fatalities, over 2,800 injuries, and over 206,000 instances of residential damage, including over 8,600 total collapses (FDMA 2019). The maximum number of evacuees was over 180,000 in Kumamoto Prefecture (CO 2019). Figure 1 shows the location of the study area. Kumamoto is located in the southern part of Japan.

Figure 2 shows the trends in property damage and injury crashes from 2010 to 2019 in Kumamoto Prefecture. Injury crashes decreased continuously, despite the earthquake in 2016. In contrast, property damage crashes increased by 6,000 in 2016 after the Kumamoto earthquake occurred. In this study, we focused on property damage crashes and analyzed their relationship with the damage caused by the earthquake.

Note that there are differences in the availability of injury-crash and property-damage-crash data. Most of the aggregated injury-crash data are in repositories open to the public and are available to researchers, whereas most property-damage-crash data are not. Therefore, we requested and obtained monthly property-damage-crash data for each of the 49 municipalities from 2015 to 2018 from the Kumamoto Prefectural Police. (Higher temporal-resolution data, such as daily and weekly data, were unavailable.)

In Japan, building damage is classified into four grades: severe (Zenkai), major (Daikibo Hankai), minor (Hankai), and slight (Ichibu-sonkai). The percentage of residential buildings with severe, major, and minor damage was used in this study. The data were published by the Kumamoto prefectural government; we calculated the percentage and illustrated it in a map.

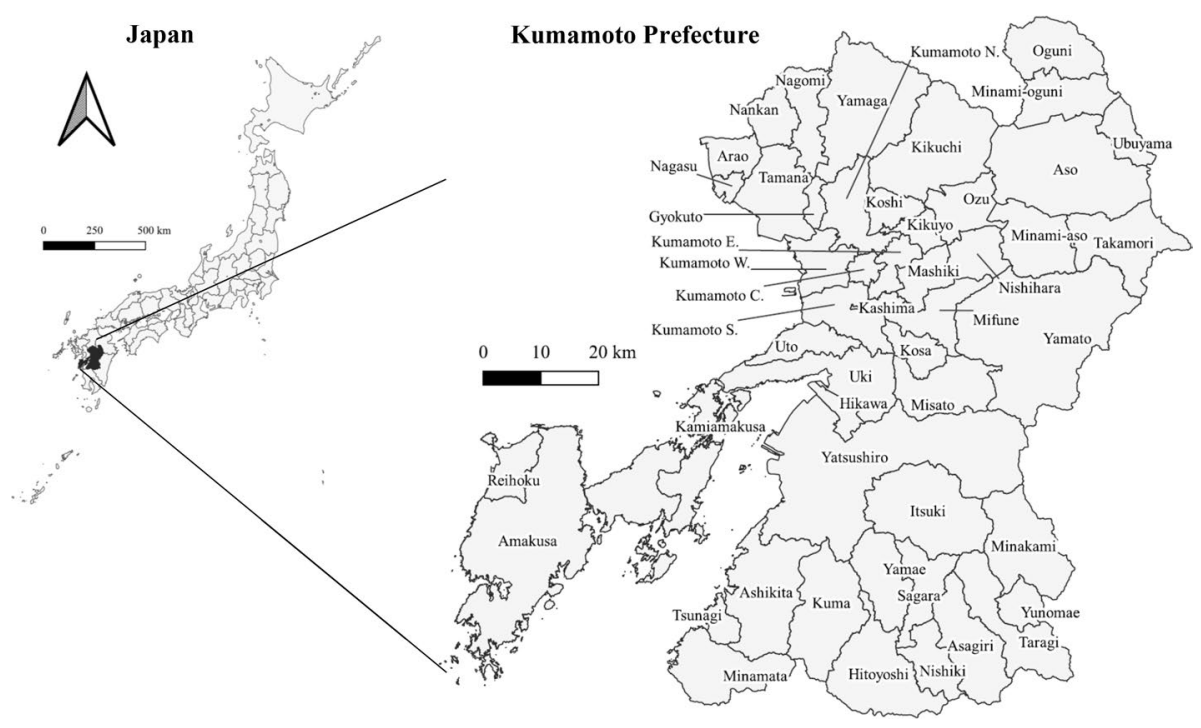

Fig. 1 Location of the study area in Japan 


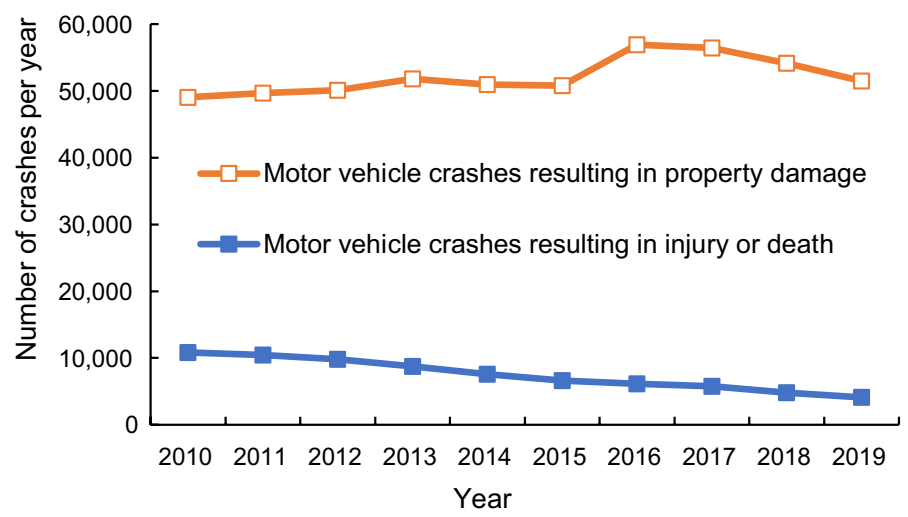

Fig. 2 Annual change in motor vehicle crashes in Kumamoto Prefecture, Japan. Source: Kumamoto Prefectural Police's Web page

\section{Method}

\subsection{Time series count model formulation}

Time series count data models have been employed in motor-vehicle-crash research. Quddus (2008) used integer-valued autoregressive Poisson models and suggested that count models are useful if the means of the counts are relatively low, as is the case with monthly motor vehicle crashes within a small geographic unit. This study used count models to analyze the monthly crash data at the municipality level based on the above report.

We used a Poisson regression model and a negative binomial regression model considering seasonality using Fourier terms. The Poisson regression model is formulated as follows:

$$
\begin{gathered}
Y_{t} \sim \operatorname{Poisson}\left(\lambda_{t}\right), \\
\log \lambda_{t}=\beta_{0}+\beta_{1} T_{t}+\beta_{2} E_{t}+\operatorname{seasonality}(t),
\end{gathered}
$$

where $Y_{t}$ is the number of monthly crashes counted at time $t$, and Poisson $\left(\lambda_{t}\right)$ is the discrete random variable following Poisson distribution with mean $\lambda_{t} . T_{t}$ is the time index during the impact period, and $E_{t}$ is 1 if the time $t$ is in the impact period and 0 otherwise. $\beta_{0}, \beta_{1}$, and $\beta_{2}$ are the parameters to be estimated. $\beta_{1}$ is the slope in the impact period and $\beta_{2}$ represents the level change at the beginning of the impact period. seasonality $(t)$ represents the seasonality in time $t$.

The negative binomial regression model assumes $Y_{t} \sim \operatorname{NegBin}\left(\lambda_{t}, \phi\right)$, where the distribution is parameterized with its mean $\lambda_{t}$ using Eq. and dispersion parameter $\phi$. A limiting case of the negative binomial distribution with $\phi \rightarrow \infty$ corresponds to the Poisson distribution. The mathematical expressions of Poisson and negative binomial regression with seasonality using Fourier terms are described in detail in Appendix 1. Zhao et al. (2019) demonstrates an application of negative binominal models in crash research.

An example of the impact model of Eq. (2) is illustrated in Fig. 3. We assumed that the number of property damage crashes is constant (i.e., has zero slope) before the earthquake, 


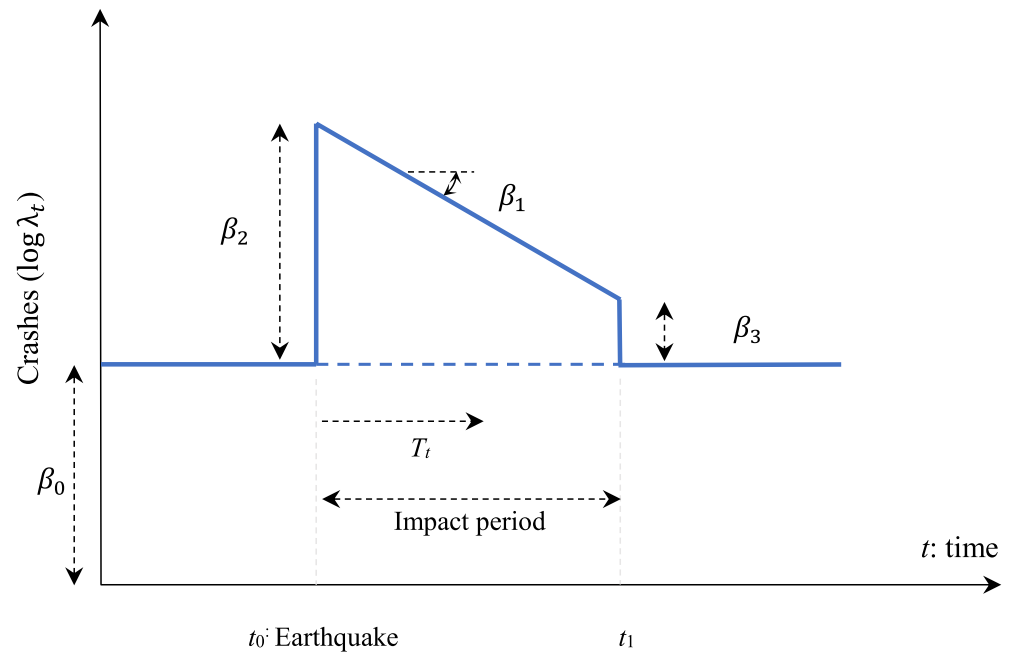

Fig. 3 Impact model considered

considering the results in Fig. 2. This assumption will prevent overfitting in the municipalitylevel data.

Note that we also investigated the use of a seasonal autoregressive integrated moving average model (Box et al. 2015; Hyndman and Athanasopoulos 2018) and count model considering serial dependence (Liboschik et al. 2017). Such models can handle autocorrelation in the residuals, but the shapes of their impact models (or intervention models) are inevitably complicated. Therefore, we adopted the model with seasonality term to handle autocorrelation in the residuals.

Many methods have been proposed to examine the seasonality of crashes. For instance, Nishi and Hino (2018) analyzed the monthly number of crashes in municipalities using statespace models and characterized the seasonality and regional differences. In this study, we used the Fourier function to describe seasonality.

\subsection{Impact model}

We estimated the model using the monthly data in each municipality; hence, the impact period would be different for each municipality. Impact model specification is portant to obtain the unbiased results (Lopez Bernal et al. 2018), and we used the following procedure to systematically determine the impact model.

The impact model should have a reasonable shape to explain earthquake effects (Fig. 3). Therefore, we assumed that the following conditions will be met.

$$
\begin{gathered}
\left|\beta_{2}\right| \geq\left|\beta_{3}\right|, \\
\beta_{2} \beta_{3} \geq 0,
\end{gathered}
$$

where $\beta_{2}$ and $\beta_{3}$ are illustrated in Fig. 3. Equation (2) estimates the parameters $\beta_{0}, \beta_{1}$, and $\beta_{2} ; \beta_{3}$ is set using the estimated $\beta_{0}$ and $\beta_{1}$. If the number of crashes increases due an earthquake, $\beta_{2}$ and $\beta_{3}$ will be positive. Meanwhile, these can be negative if an earthquake 
reduces the number of crashes. If Eq. (3) does not hold, it means that the impact of the earthquake increases with time, which is unreasonable. If Eq. (4) does not hold, $\beta_{2}$ is positive and $\beta_{3}$ is negative (or $\beta_{2}$ is negative and $\beta_{3}$ is positive) indicating a zigzag line, which is also unreasonable, implying overfitting.

The impact period is determined for each municipality that maximizes the Akaike Information Criteria (AIC) while satisfying Eqs. (3) and (4). If the impact period is longer than the sampled period, the model does not undergo a structural change; whereas, if the impact period is shorter than the sampled period, the model undergoes a structural change. The standard AIC should not be used to select models with possible presence of multiple structural changes; Kurozumi and Tuvaandorj (2011) proposed a modified AIC, which can be employed in this case. They showed that a value of six times the number of structural changes should be added to the modified criteria. We adopted this modified AIC to determine the impact period for each municipality.

We computed the relative risk (RR) and its 95\% confidence intervals (CI) from the final model.

$$
R R=\exp \left(\beta_{0}+\beta_{2}\right) / \exp \left(\beta_{0}\right)=\exp \left(\beta_{2}\right)
$$

An exponential function was used to change the log-scale in Eq. (1) to a normal scale. The RR indicates the change in the number of crashes caused by an earthquake.

\subsection{Procedure}

As it is for other statistical methods, a larger number of data points and observations are better for ITS. A minimum of nine data points for pre- and post-intervention and at least 100 observations per data point are recommended (Jandoc et al. 2015). Our data satisfy the nine data point requirements for pre- and post-intervention (i.e., earthquake); however, some municipalities with a small population have less than 100 observations per data point. Hence, the aggregation of municipalities is recommended, although arbitrary aggregation will yield the biased results and may eliminate the location-specific features of results. In this paper, we proposed the following procedure to systematically analyze the data and obtain robust results.

Step: 1 Estimate the best models for each municipality while satisfying the impact model requirements. Compute the RR and CI for each municipality.

Step: 2 Classify the municipality using the similarity of RR, housing damage, and geographical proximity.

Step: 3 Estimate the models for each classified municipality and obtain the RR and CI.

The details of Step: 1 are as follows.

Step: 1.1. Change the impact period from $6,9,12, \ldots, 33$ months and estimate the Poisson and negative binomial models for each municipality. Models with $\beta_{1}=0$ are also estimated to consider the possible models with no slope change.

Step: 1.2. Select the model with the lowest modified AIC while satisfying the model requirements.

Similar steps are adopted in Step: 3. 
This procedure can be considered to be a meta-analysis of municipality-level results (Zhang et al. 2019). We did not include the estimated parameter of 49 municipality-level models in this paper to save space, but we have presented their RR and 95\% CI. We comprehensively illustrated, for each classified municipality, the data, the estimated parameters of the model, their RR, and 95\% CI. A statistical significance level of 0.05 was adopted in this study. We used 'MASS' and 'tsModel' in R4.0.2 software packages for the ITS analysis, and QGIS 3.14 to geographically illustrate the data.

\section{Results}

Figure 4 shows the percentage of residential buildings with severe, major, and minor damages in the municipalities. This figure illustrates the impact of earthquake damage. Mashiki and Nishihara experienced the highest impact in the 2016 Kumamoto earthquake, and these and their surrounding areas had higher damage.

The RRs are computed using ITS analysis for each municipality. Figure 5 shows their distribution, whereas Fig. 6 shows their CIs with a decreasing order of housing damage.

Housing damage
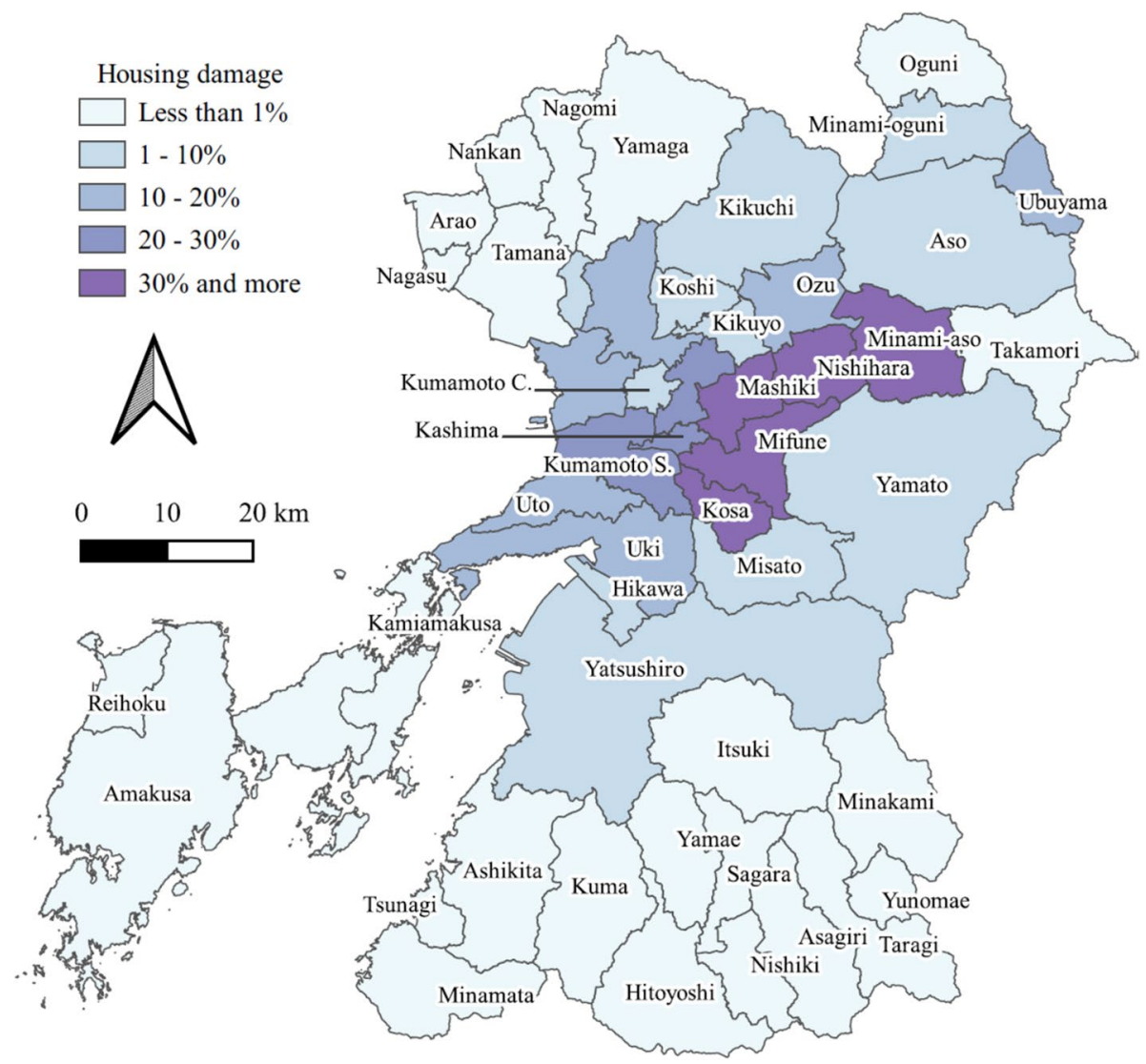

Fig. 4 Percentage of residential buildings damaged by the 2016 Kumamoto earthquake Source: Built using the data published by the Kumamoto Prefectural government 
RR

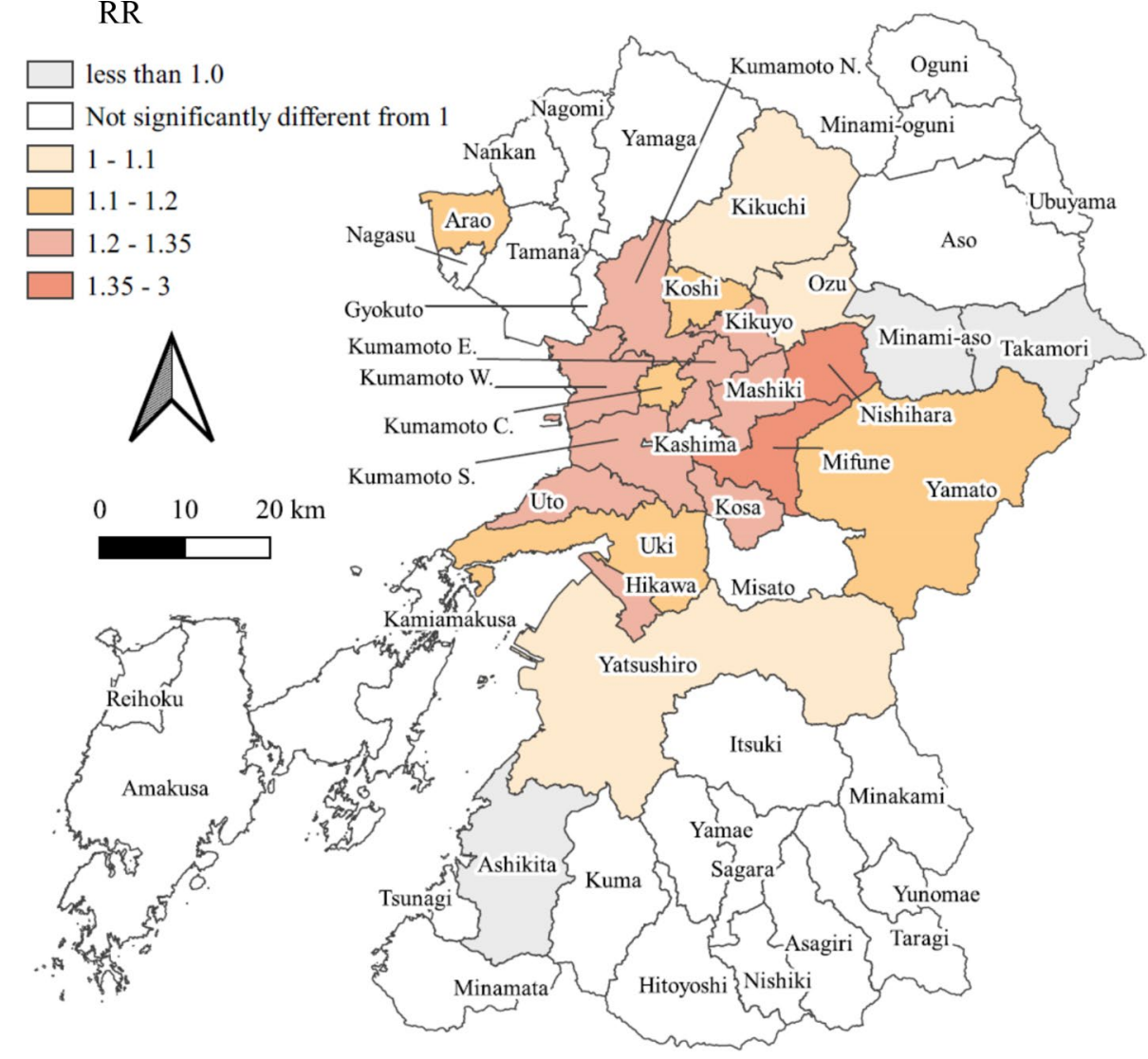

Fig. 5 Relative risk of property damage crashes by the Kumamoto earthquake

If the CIs contain 1.0, the estimated RR is not statistically different from 1.0, indicating no change in the crash risk. The estimated RR is statistically meaningless in this case, and Fig. 5 shows blanks for such municipalities. The most heavily damaged area reveals a higher crash increase, whereas most of the slightly damaged areas show no statistically significant difference in the crash (Figs. 4 and 5).

The results in Fig. 5 contain some outliers: Ashikita, Kashima, Misato, and Arao. The reason for the outliers can be explained as follows. The average observations per month for Ashikita, Kashima, and Misato are 20.5, 61.2, and 13.7, respectively. The observations are smaller than the recommended level of 100. The average observation for Arao is 111.7, which is just above 100. These lower observations can explain the trends of the abovementioned areas that are different from the neighborhood.

The municipality-level results are aggregated to obtain more robust results. Using these results and geographical proximity, the municipalities are classified into four areas as shown in Fig. 7, namely 'heavily affected area,' 'affected area,' 'Minami-aso \& Takamori,' and 'Others.' We adopt the following definitions: A municipality with damage to more than $30 \%$ of housing (Fig. 4) is classified as part of the 'heavily affected area' (with the exception of Minami-aso, where there was a statistically significant decrease in crashes 
Relative risk

$\begin{array}{lllr}0 & 1 & 2 & 3\end{array}$

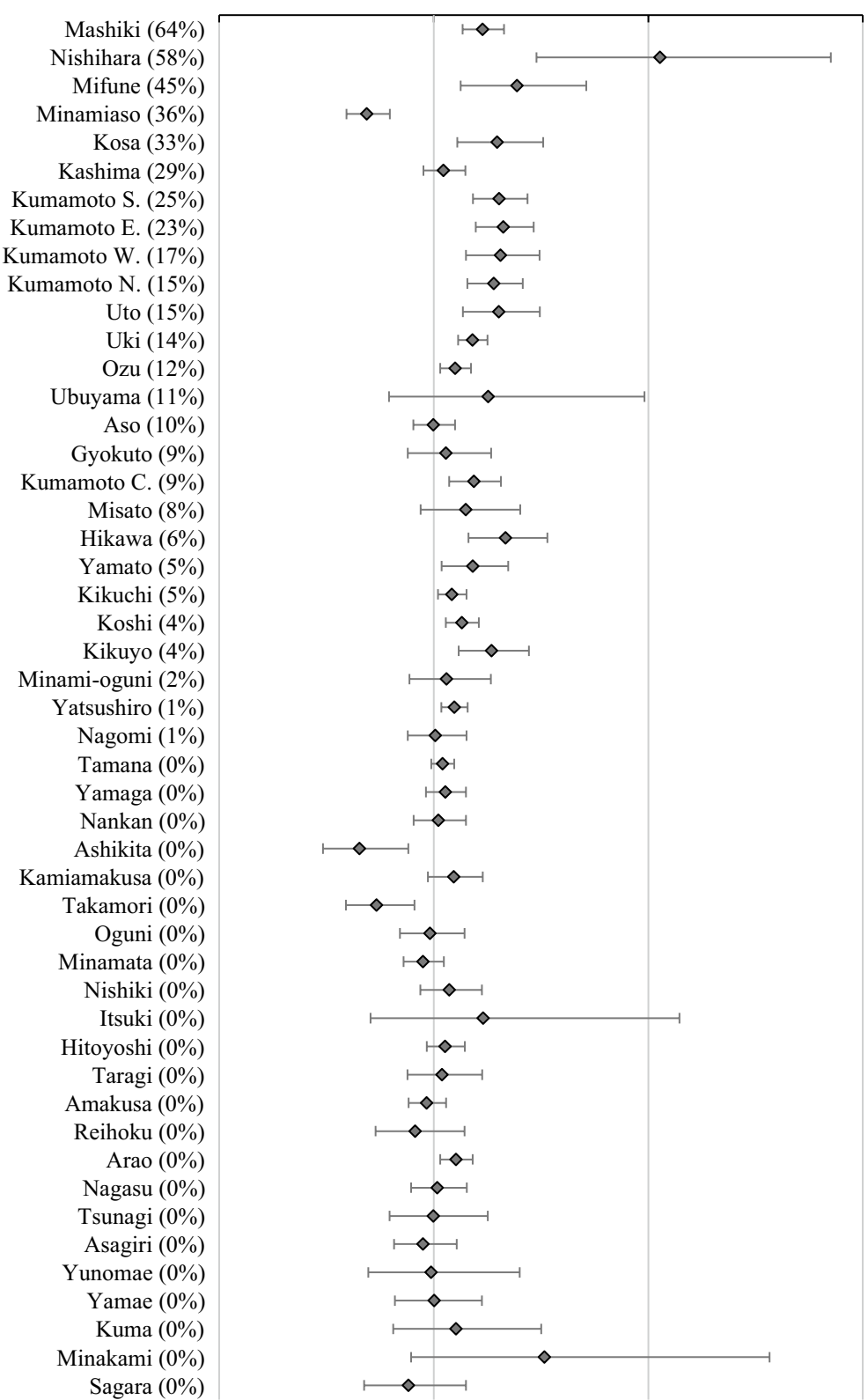

Fig. 6. 95\% Confidence intervals of the relative risk of crash for the municipalities in Kumamoto. Note: The percentages in parentheses indicate housing damaged by the earthquake in the municipality

(Fig. 5)). A municipality with damage to $1-30 \%$ of housing (Fig. 4) and with a statistically significant increase in crashes (Fig. 5) is classified as part of the 'affected area.' Minamiaso and Takamori, which had a statistically significant decrease in crashes, are placed in a 
Fig. 7 Classification of municipalities

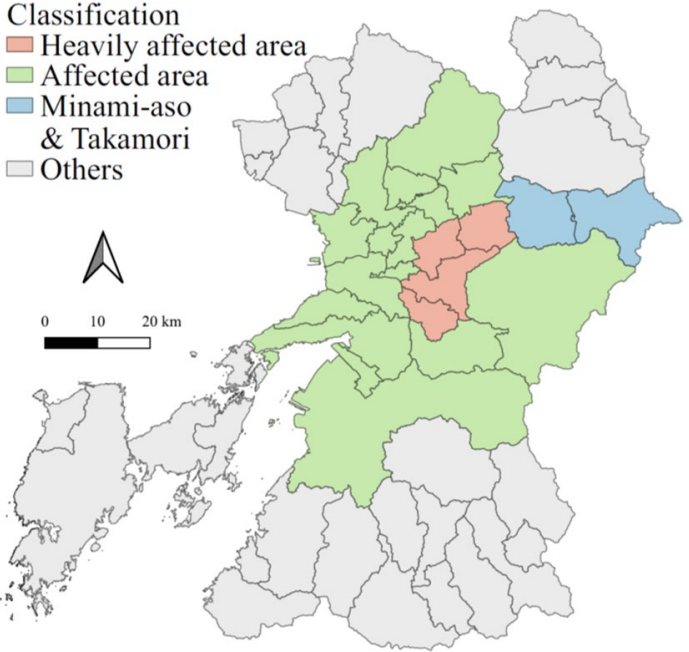

special category. The outliers mentioned before-Ashikita, Kashima, Misato, and Arao-are placed in the same categories as the largest number of adjacent municipalities.

Consequently, the 'heavily affected area' includes Mashiki, Nishihara, Mifune, and Kosa, and each had more than $30 \%$ of housing damage (Fig. 4). The 'affected area' surrounds the 'heavily affected area,' and most of the municipalities had 5-30\% of housing damage (Fig. 4). 'Minami-aso \& Takamori' showed a decrease in crashes, although Minami-aso had 36\% of housing damage. 'Others' include areas that are not classified in the three areas, and most of these areas had marginal damage.

ITS analysis was performed for the classified four areas and the total area. Table 1 presents the estimated parameters of the time series count model. In the total area, $\beta_{2}=0.18$ is positive and statistically significant, which indicates an uplift at the beginning of the impact period-this represents the immediate effect of the earthquake. In contrast, $\beta_{1}=-0.003$ is negative and statistically significant, which indicates a downward slope change in the impact period (as illustrated in Fig. 3) — this represents the long-term impact of the earthquake. Similarly, in the heavily affected and affected areas, the statistically significant positive estimates of $\beta_{2}$ indicate an uplift at the beginning of the impact period; the statistically significant negative estimates of $\beta_{1}$ indicate a downward slope change in the impact period. In 'Minami-aso \& Takamori,' $\beta_{1}$ is statistically insignificant and is excluded, whereas the statistically significant negative estimates of $\beta_{2}$ indicate a downward level change in the impact period. The minimum AIC criteria were used to select the Poisson model in 'Minami-aso \& Takamori,' and the negative binomial model in the other four areas with statistically significant estimates of $\phi$ indicates over-dispersion.

Figure 8 shows the estimated and counterfactual lines, along with the actual data; Fig. 9 gives a summary of the estimated CIs. The 'heavily affected area' and 'affected area' showed increases in crashes immediately after the earthquake, and the impacts gradually decreased toward the end of 2018 (Fig. 8). Fourier term appears to represent a part of seasonality; see Appendix 2 for a discussion of the autocorrelations in the residuals. The estimated RR is 1.48 (95\% CI: 1.29, 1.71) in the 'heavily affected area,' 1.25 (95\% CI: 1.15 , 1.36) in the 'affected area,' and 1.20 (95\% CI: 1.10, 1.30) in the total area (Fig. 9). The RR in 'others' was not statistically significant from 1.0. 'Minami-aso \& Takamori' exhibited a 


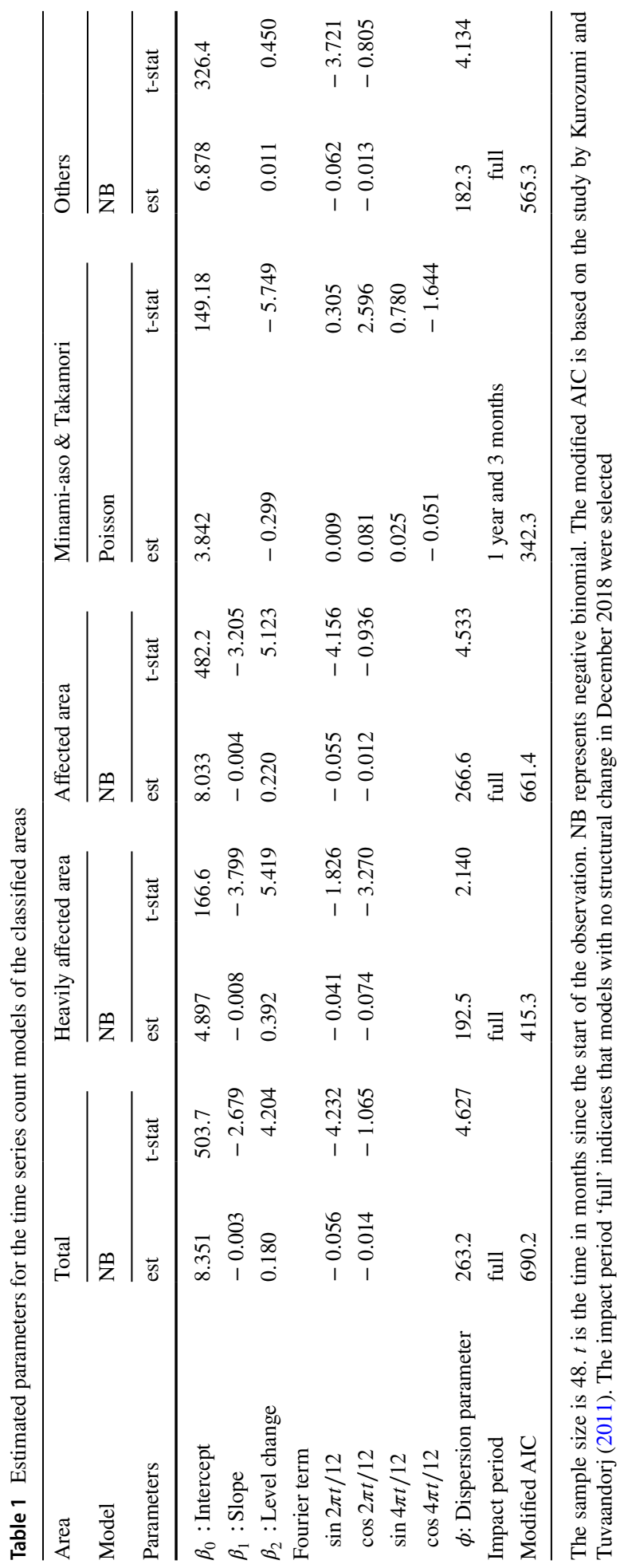


Heavily_affected_area
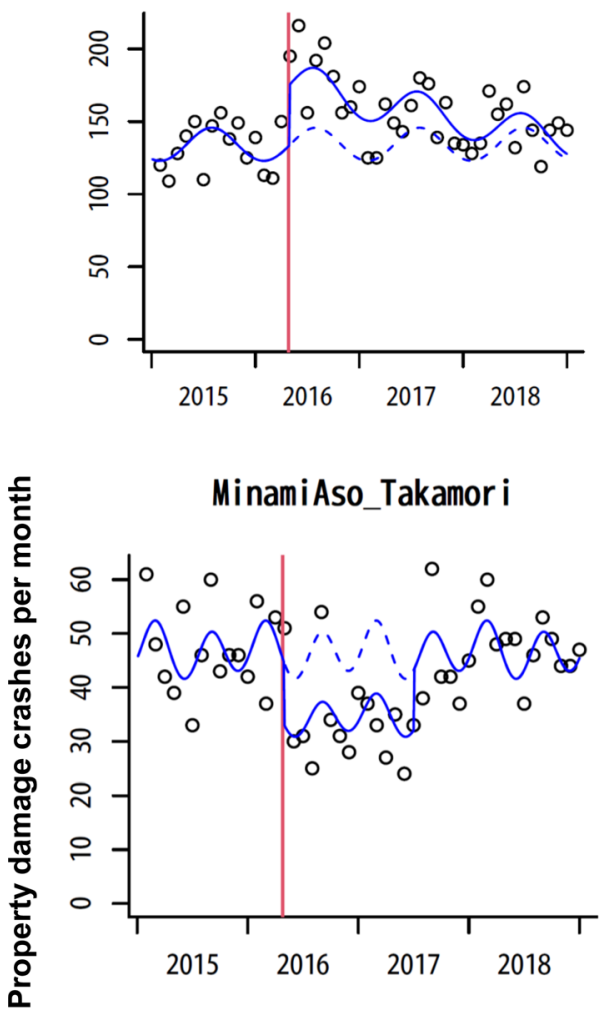

Total

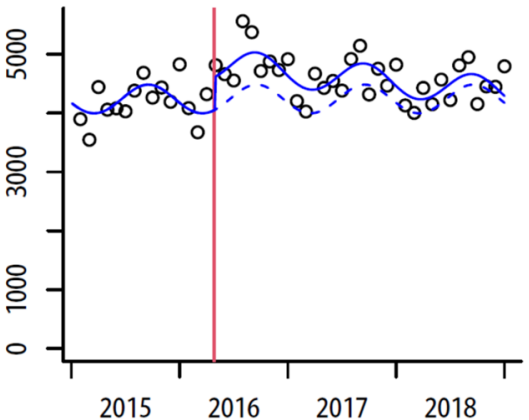

Affected_area

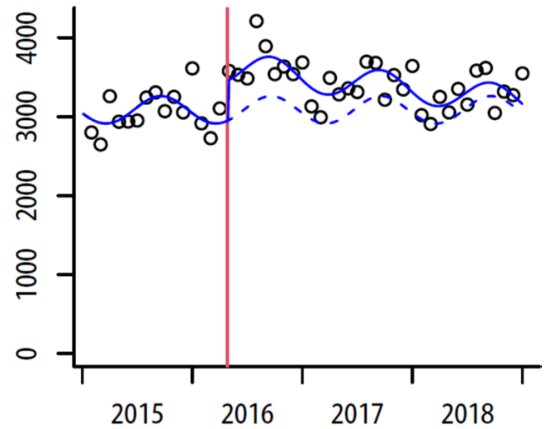

Others

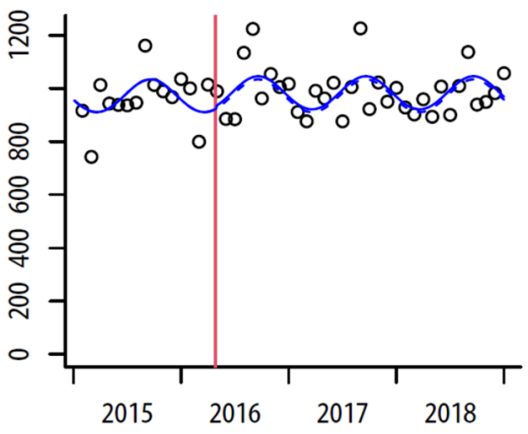

\section{Year}

Fig. 8 Trends in property damage crashes for each classified municipality (crashes per month). Note: The vertical red line is the time of earthquake occurrence. The dotted blue line is the counterfactual line. The solid blue line is the seasonalized predicted trend 


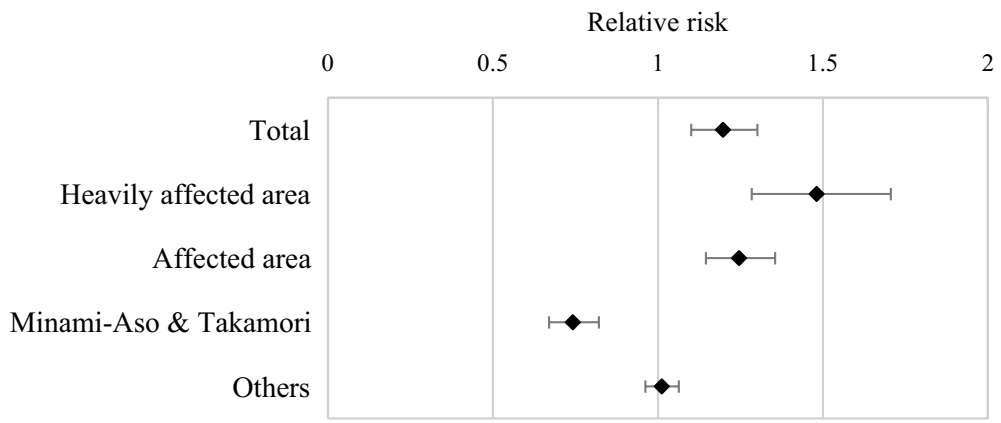

Fig. 9 Confidence intervals of relative risk of crashes in the classified areas

different trend, with a level drop from April 2016 to June 2017 ( $R R=0.74,95 \%$ CI: 0.67, $0.82)$.

\section{Discussion}

The 'heavily affected area' exhibited a higher RR than the 'affected area,' although the difference is not statistically significant (Fig. 9). This could be partly due to the small observations per month, with an average of 149.3 , in the 'heavily affected area.' The estimated $\beta_{1}$ and $\beta_{2}$ values for the 'heavily affected area' were approximately twice of those for the 'affected area' (Table 1), which implies that the earthquake impact lasted for similar periods of time in these two areas. This may seem counterintuitive, because the stress on victims caused by the earthquake might be expected to last longer in the 'heavily affected area,' where many victims lost their homes and had to live in temporary housing. The current available data are not sufficient to examine this issue; detailed data with crash causes may reveal the reason in the future.

The area of 'others' showed no difference in the crashes before and after the earthquake. The results in Fig. 9 and the maps in Fig. 4 and Fig. 5 provide clear evidence of the positive association of earthquake damage and crash increase if 'Minami-aso \& Takamori' is not considered.

The results of 'Minami-aso \& Takamori' show that crashes dropped after the earthquake and returned on July 2017, resulting in an estimated impact period of 1 year and 3 months; this can be explained as follows. The area is a mountainous area, and bridges, tunnels, and roads that are on the main gate routes to the area from the Kumamoto metropolitan area, were damaged in April 2016 due to the earthquake. The Aso-ohashi bridge collapsed, the Tawarayama tunnel and the Aso-choyo-ohashi (ACO) bridge were damaged. These collapsed and damaged structures could have reduced the number of vehicles entering the area, although the actual number was not available. A reduction in the number of vehicles would have resulted in a decrease in crashes. These damaged routes have been gradually restored. The Tawarayama tunnel was temporally restored in December 2016, and the ACO bridge was restored in August 2017. The ACO bridge is located near the Asoohashi bridge, and serves as detours for the Aso-ohashi bridge. Thus, restoring the ACO bridge in August 2017 seems to have paved the way for vehicles entering the area, resulting in crashes of similar levels before the earthquake. 
The closure of main gate routes to the 'Minami-aso \& Takamori' may also explain the considerable crash increase in Nishihara (Figs. 5, 6). Nishihara encompasses the 'Green Road,' which was also damaged by the earthquake but quickly recovered in April 2016. The road served as a detour to the damaged gate routes, which could have increased the number of vehicles in the town and caused congestion; this may have resulted in the crash increase.

Aso and Ubuyama, which had $10 \%$ and $12 \%$ housing damage, respectively (Fig. 6), revealed an insignificant crash change. This appears to be caused by the offsetting effect of reduced traffic due to the closure of the road into the area and potential increase in crashes due to earthquake stress there.

The Kyushu Expressway, which passes through the Kumamoto Prefecture from North to South, was damaged by the earthquake, causing a part of the road to be closed in April 2016; this may partly explain the crash increase in Arao (Fig. 5). The closure produced heavy congestion in the Kumamoto metropolitan area, and traffic detoured from the damaged Expressway was sent through Arao (Kawasaki et al. 2017). The higher RR in Arao can be attributed to the increased traffic on the detour.

In summary, our results imply that earthquake damage and the number of crashes are associated as follows: In areas where the main routes were damaged by an earthquake, the number of vehicles entering the areas and crashes decreased. These values returned to the original level as the damaged routes were restored. In the other areas affected by an earthquake, the number of crashes increased in the affected area. These increases were high, particularly when an earthquake occurs, and the increases gradually disappeared over time. In areas that experienced a minimal effect of the earthquake, the number of crashes remained unchanged.

The results are consistent with those reported in the literature. Hino et al. (1997a) reported an increase in crashes following the 1995 Great Hanshin-Awaji Earthquake. They found that the annual number of injury crashes increased by $17 \%$ compared with the previous year in 1995 in the Kobe area. In some months, a 30\% increase was reported compared with the same month of the previous year. The authors did not report changes in property damage crashes. Hagita and Yokozeki (2019) analyzed the number of crashes during major earthquakes in Japan from 1995 to 2008 and found that injury crashes generally increased in areas with high population densities. They also reported a decrease in injury crashes in some areas with low population densities. Casey et al. (2019) reported a $4.6 \%$ increase in crashes in the highly affected areas in the month following human-induced earthquakes. Although the majority of these studies did not focus on property damage crashes but on injury crashes, the results are generally consistent with the findings of the present study: crashes increased after the earthquake. The decrease in injury crashes in low population density areas (Hagita and Yokozeki 2019) can be explained using a similar situation in 'Minami-aso \& Takamori' in this study; that is, the traffic was reduced because of road damage.

The present study did not explore the reason for crash-rate change. Casey et al. (2019) postulated that anxiety, stress, distraction, and sleep deprivation experienced by people due to the occurrence of earthquakes may lead to dangerous driving behavior and motor vehicle crashes. To examine this issue, the questionnaire surveys conducted by Ueno et al. (1997) and Hino et al. (1997b) on drivers following the 1995 Great Hanshin-Awaji Earthquake are useful. They showed that more than $80 \%$ of drivers perceived an increased risk of crashes, and drivers also reported that the main reasons are violation of traffic rules, increased traffic congestion, and road damage and construction. This could be a possible reason for the increase in crashes during the Kumamoto earthquake. Residents living in the affected area 
were in a stressful condition due to the earthquake. The disaster victims who lost their houses and were staying at evacuation centers and temporary housing may not have slept well. Many evacuees stayed overnight in their cars after the Kumamoto earthquake (Araki et al. 2017; Inazuki 2018). These stressful conditions may cause careless driving resulting in crashes, although a decisive conclusion requires additional surveys. Recent technologies, which can measure drowsiness, distraction (Soares et al. 2020), sleepiness, and mental fatigue (Hu and Lodewijks 2020), may be useful to examine this issue in future disasters.

The present study focused on property damage crashes. Injury crashes revealed no clear change after the earthquake (Fig. 2). The difference in the change between property damage and injury crashes is still unclear. The first author of this paper shared the findings of some existing studies (Hino et al. 1996, 1997a; Wada et al. 1997) with the police immediately after the earthquake, and the police increased patrol in the affected area. The findings were also presented in local newspapers, radio, and TV, and recommendations for safe driving were made. These activities may help reduce heavy crashes, although validating them is beyond the scope of this study. Nevertheless, safe-driving alerts after disasters appear to be important.

The present study also has several limitations. This work is a retrospective study as it was initiated after the earthquake has occurred. Thus, several data are inevitably unavailable. First, the traffic flow data for each municipality before and after the earthquake were unavailable. The increase in crashes can be attributed to an increase in traffic flow because of rescue vehicles, volunteers from other areas, and increased trips by victims. Motor-vehicle-crash numbers can increase even if the crash probability remains constant. To investigate this issue, the crash data should be offset by traffic flow data in future work. It is noteworthy, however, that motor-vehicle-crash safe-driving alerts during a disaster are important, whether the reason for the increase is traffic flow increase or risk increase.

Second, the monthly property-damage-crash data for each municipality were not available before 2015, making it difficult to construct models before the earthquake. We considered that this issue is not significant because of the stable yearly rate of property damage crashes before 2015 (Fig. 2), justifying the assumption of a constant (i.e., zero slope) regression line before the earthquake. However, controlling for long-term trends using more data would be preferable in the future.

Third, property-damage-crash microdata, containing times, locations, weather, damage levels, crash types, and other relevant factors, are not available, and variations after the earthquake were neglected. The injury-crash statistics in Japan include detailed data for crashes, such as the time, vehicle type, driver attributes, and latitude and longitude of the crash site. By contrast, the current property-damage-crash statistics in Japan provide only macro-level data, as shown in the monthly municipality-based counts. Developing a detailed property-damage-crash database will help to improve the analysis in future studies. For example, the analysis in this study showing that earthquake damage to housing is correlated with crashes implicitly assumes that drivers involved in a crash live in the municipality of the crash, but actually they may not. Future work should analyze microdata for crashes, which contains drivers' residences. In addition, data with higher temporal resolution, such as daily and weekly data, will be useful and produce more informative results in ITS analysis. Daily data with weather conditions would be particularly effective in controlling for the cause of the crash.

Fourth, the analysis in this study is based on police data. A possible problem of using police data is that some property damage crashes may not be reported to the police, although injury crashes will always be reported. If the unreported rate is unchanged before and after the earthquake, our results are valid. The change in the rate is beyond the scope 
of this study, but analysis using other types of data, such as data obtained from car repair shops and car insurance companies, may offer a different view.

Our study makes a strong contribution to the literature, even with these limitations. This paper reports a clear statistical association between earthquake damage and increase in motor vehicle crashes using ITS. The findings of this study highlight the importance of motor-vehicle-crash alerts after an earthquake.

\section{Conclusion}

In this study, we examined motor vehicle crashes following the 2016 Kumamoto earthquake and found that the number of crashes resulting in injury or death decreased, despite the earthquake, but crashes resulting in property damage increased after the earthquake. Interrupted time series analysis demonstrated that the number of property damage crashes increased even more in the heavily affected areas $(\mathrm{RR}=1.48,95 \% \mathrm{CI}: 1.29,1.71)$ than in the affected area $(\mathrm{RR}=1.25,95 \% \mathrm{CI}: 1.15,1.36)$. A mountainous area showed a reduction in property damage crashes after the earthquake despite its heavy damage $(R R=0.74$, 95\% CI: $0.67,0.82$ ), which can be attributed to the closure of its main gate routes. These findings can be useful for planning traffic safety measures during and after earthquake disasters.

\section{Appendix 1}

The probability function for the Poisson model $Y_{t} \sim \operatorname{Poisson}\left(\lambda_{t}\right)$ is given as follows:

$$
P\left(Y_{t}=y \mid \lambda_{t}\right)=\frac{\lambda_{t}^{y} \exp \left(\lambda_{t}\right)}{y !} .
$$

Its mean and variance are equal $\left(E\left(Y_{t}\right)=\operatorname{Var}\left(Y_{t}\right)=\lambda_{t}\right)$.

The probability function for the negative binomial model $Y_{t} \sim \operatorname{NegBin}\left(\lambda_{t}, \phi\right)$, its mean, and variance are given as follows:

$$
\begin{gathered}
P\left(Y_{t}=y \mid \lambda_{t}, \phi\right)=\frac{\Gamma(\phi+y)}{\Gamma(\phi) y !} \frac{\lambda_{t}^{y} \phi^{\phi}}{\left(\lambda_{t}+\phi\right)^{\phi+y}} \\
E\left(Y_{t}\right)=\lambda_{t}, \operatorname{Var}\left(Y_{t}\right)=\lambda_{t}+\lambda_{t}^{2} / \phi .
\end{gathered}
$$

The model with $\phi \rightarrow \infty$ reduces to the Poisson model (Venables and Ripley 2002).

The seasonality can be generally expressed as follows using Fourier terms.

$$
\operatorname{seasonality}(t)=\sum_{j=1}^{J}\left(a_{j} \sin \left(\frac{2 \pi j t}{12}\right)+b_{j} \cos \left(\frac{2 \pi j t}{12}\right)\right),
$$

where $t$ is the time in months since the start of the observation, and $a_{j}$ and $b_{j}$ are the parameters to be estimated. To prevent overfitting, we set the maximum $J=2$ in this study. 


\section{Appendix 2}

To address the autocorrelation in residuals, we conducted Ljung-Box test with null hypothesis 'no autocorrelation' using the test statistic $Q^{*}$ (Box et al. 2015; Hyndman and Athanasopoulos 2018)

$$
Q^{*}=T(T+2) \sum_{k=1}^{h}(T-k)^{-1} r_{k}^{2},
$$

where $r_{k}$ is the autocorrelation at lag $k$ in the residuals, $h$ is the number of lags being tested, and $T$ is the sample size. Following Hyndman and Athanasopoulos (2018), we set $h=10$.

Table 2 lists the results for the model with Fourier terms (Fourier model). Unfortunately, the null hypothesis (no autocorrelation) was rejected for the Fourier model in each area. We also confirmed some spikes at lag 6 or 12 in the autocorrelation function and partial autocorrelation function of the residuals. This indicates that Fourier terms may not sufficient to address seasonality fully.

Therefore, a model with monthly dummies (monthly dummy model) was tried. In this model, the seasonality was expressed as

$$
\operatorname{seasonality}(t)=\sum_{j=2}^{12} c_{j} \operatorname{month}(t, k),
$$

where $c_{j}$ is the parameter to be estimated and month $(t, k)$ is the monthly dummy, taking value 1 when the time $t$ is month $k$, and 0 otherwise. The data for January were chosen as the base, i.e., $c_{1}=0$.

The results for the monthly dummy model are also presented in Table 2, along with its estimated RRs and 95\% confidence intervals. The results suggest no autocorrelation remained in the residual except in the 'Others' area. Furthermore, the RRs for the monthly dummy model were almost identical to those for the Fourier model; their difference is less than 0.04 . The estimated $95 \%$ CIs for the monthly dummy model were narrower than those from the Fourier model, and, thus, the 'heavily affected area' exhibited a statistically significant higher RR than the 'affected area.' 'Others' exhibited an RR not statistically different from 1.0 in both models.

Table 2 Relative risk (RR), 95\% confidence intervals (CI), and residual diagnostics for estimated models

\begin{tabular}{|c|c|c|c|c|c|c|}
\hline & \multicolumn{3}{|c|}{ Model with Fourier term } & \multicolumn{3}{|c|}{ Model with monthly dummy } \\
\hline & $\mathrm{RR}$ & $95 \%$ CI & $Q^{*}(p$ value $)$ & $\mathrm{RR}$ & $95 \% \mathrm{CI}$ & $Q^{*}(p$ value $)$ \\
\hline Total & 1.197 & $(1.101,1.301)$ & $53.91(<0.001)$ & 1.208 & $(1.170,1.247)$ & $14.29(0.160)$ \\
\hline Heavily affected area & 1.480 & $(1.285,1.706)$ & $24.97(0.005)$ & 1.494 & $(1.344,1.660)$ & $9.51(0.485)$ \\
\hline Affected area & 1.246 & $(1.145,1.355)$ & $43.29(<0.001)$ & 1.259 & $(1.219,1.299)$ & $10.99(0.358)$ \\
\hline Minami-aso \& Takamori & 0.742 & $(0.670,0.821)$ & $20.16(0.028)$ & 0.734 & $(0.663,0.814)$ & $14.25(0.162)$ \\
\hline Others & 1.012 & $(0.962,1.063)$ & $38.07(<0.001)$ & 1.049 & $(0.994,1.108)$ & $28.84(0.001)$ \\
\hline
\end{tabular}
with Fourier term and monthly dummy

Note: $Q^{*}$ is the statistic of the Ljung-Box test (see Eq. (10)). The estimated impact periods are identical to those in Table 1 (e.g., 1 year and 3 months in Minami-aso \& Takamori) 
We conclude that demonstrating the results of the Fourier model as final ones is preferred, for the following reasons. Although the monthly dummy model produced results with no autocorrelations in the residuals, it included a large number of parameters. The seasonalized trend predicted by the monthly dummy model contained implausible jumps (Bhaskaran et al. 2013) between adjacent months; this contrasts with the smooth changes predicted by the Fourier model (Fig. 8). The monthly dummy model can be overfitted, given its small sample size (48 months). In contrast, the estimated RRs for both models are similar, meaning that the results of the Fourier model are unaffected by the autocorrelations in the residuals. Thus, we conclude that the Fourier model is the better choice.

Acknowledgements The authors thank the Kumamoto Prefectural police for providing the data for this study and Hajime Watanabe for the analysis support. We also thank Toshimori Otazawa and the participants at 58th and 60th JSCE IP Conferences 2018, 2019, CWMD conference 2019, and ARSC 2020 for their helpful comments. The comments from two anonymous reviewers were helpful in improving the manuscript. The usual disclaimer applies.

Author Contributions Takuya Maruyama contributed to conceptualization, formal analysis, investigation, methodology, software, visualization, writing - original draft, writing - review and editing, and supervision. Kazutake Taguchi contributed to data curation, formal analysis, and writing - original draft.

Funding This work was supported by the research fund at Kumamoto University.

Availability of data and material The data that support the findings of this study are available from the corresponding author upon reasonable request.

Code availability The code that support the findings of this study are available from the corresponding author upon reasonable request.

\section{Declarations}

\section{Conflict of interest None.}

Open Access This article is licensed under a Creative Commons Attribution 4.0 International License, which permits use, sharing, adaptation, distribution and reproduction in any medium or format, as long as you give appropriate credit to the original author(s) and the source, provide a link to the Creative Commons licence, and indicate if changes were made. The images or other third party material in this article are included in the article's Creative Commons licence, unless indicated otherwise in a credit line to the material. If material is not included in the article's Creative Commons licence and your intended use is not permitted by statutory regulation or exceeds the permitted use, you will need to obtain permission directly from the copyright holder. To view a copy of this licence, visit http://creativecommons.org/licenses/by/4.0/.

\section{References}

Adeel Z, Alarcón AM, Bakkensen L et al (2020) Developing a comprehensive methodology for evaluating economic impacts of floods in Canada, Mexico and the United States. Int J Disaster Risk Reduct 50:101861. https://doi.org/10.1016/j.ijdrr.2020.101861

Araki Y, Udagawa S, Takada Y et al (2017) A Case study on response to evacuees in non-designated evacuation shelters in Mashiki town in the 2016 Kumamoto earthquake. J Soc Saf Sci 31:167-175. https:// doi.org/10.11314/jisss.31.167

Bhaskaran K, Gasparrini A, Hajat S et al (2013) Time series regression studies in environmental epidemiology. Int J Epidemiol 42:1187-1195. https://doi.org/10.1093/ije/dyt092

Box GEP, Jenkins GM, Reinsel GC, Ljung GM (2015) Time series analysis: forecasting and control, 5th edn. John Wiley \& Sons 
Casey JA, Elser H, Goldman-Mellor S, Catalano R (2019) Increased motor vehicle crashes following induced earthquakes in Oklahoma, USA. Sci Total Environ 650:2974-2979. https://doi.org/10.1016/j. scitotenv.2018.10.043

Chen X, Chang CP (2020) The shocks of natural hazards on financial systems. Nat Hazards. https://doi.org/ $10.1007 / \mathrm{s} 11069-020-04402-0$

CO (2019) Damages by the 2016 Kumamoto earthquake. Cabinet Office, Government of Japan. http://www. bousai.go.jp/updates/h280414jishin/

Eckhardt D, Leiras A, Thomé AMT (2019) Systematic literature review of methodologies for assessing the costs of disasters. Int J Disaster Risk Reduct 33:398-416. https://doi.org/10.1016/j.ijdrr.2018.10.010

FDMA (2019) Summmary of the 2016 Kumamoto Earthquake. Fire and Disaster Management Agency, Japan. https://www.fdma.go.jp/disaster/info/items/kumamoto.pdf

Gigerenzer G (2004) Dread risk, September 11, and fatal traffic accidents. Psychol Sci 15:286-287. https:// doi.org/10.1111/j.0956-7976.2004.00668.x

Grundy C, Steinbach R, Edwards P et al (2009) Effect of $20 \mathrm{mph}$ traffic speed zones on road injuries in London, 1986-2006: controlled interrupted time series analysis. BMJ 339:b4469-b4469. https://doi. org/10.1136/bmj.b4469

Hagita K, Yokozeki T (2019) Traffic accidents analysis before and after mega earthquakes concerning road traffic environment. JSTE J Traffic Eng 5:30-38. https://doi.org/10.14954/jste.5.1_30

Helton WS, Head J (2012) Earthquakes on the mind: implications of disasters for human performance. Hum Factors J Hum Factors Ergon Soc 54:189-194. https://doi.org/10.1177/0018720811430503

Hino Y, Masuda K, Yoshida N (1996) Analysis of traffic accidents after the Great Hanshin Awaji Earthquake and the concept of traffic operation during disasters. Proc 16th JSTE Conf, vol 16, pp 85-88

Hino Y, Ueno S, Hosomi K, et al (1997a) Some issues of traffic management based on traffic accidents as secondary disaster after the Hanshin-Awaji Earthquake. Pap Hanshin-Awaji Earthquake, JSCE Infrastruct Plan Comm, pp 287-292

Hino Y, Ueno S, Wada M, Miyori K (1997b) Some issues caused by car usage and traffic control after the earthquake disaster. JSCE Proc Hanshin-Awaji Earthq 2:505-512

Hu X, Lodewijks G (2020) Detecting fatigue in car drivers and aircraft pilots by using non-invasive measures: the value of differentiation of sleepiness and mental fatigue. J Saf Res 72:173-187. https://doi. org/10.1016/j.jsr.2019.12.015

Hyndman RJ, Athanasopoulos G (2018) Forecasting: principles and practice, 2nd edn. OTexts: Melbourne, Australia

Iida Y, Kurauchi F, Shimada H (2000) Traffic management system against major earthquakes. IATSS Res 24:6-17. https://doi.org/10.1016/s0386-1112(14)60024-8

Inazuki T (2018) Reasons and hardships of living out of a car after the Kumamoto earthquake. J Soc Soc West Japan 16:5-22. https://doi.org/10.32197/sswj.16.0_5

Jandoc R, Burden AM, Mamdani M et al (2015) Interrupted time series analysis in drug utilization research is increasing: systematic review and recommendations. J Clin Epidemiol 68:950-956. https://doi.org/ 10.1016/j.jclinepi.2014.12.018

Jibiki Y, Ohara M, Tanaka A, Furumura T (2015) Analysis of drivers' behaviors on highways in Great East Japan Earthquake. J Soc Saf Sci 26:27-35. https://doi.org/10.11314/jisss.26.27

Jiménez Martínez M, Jiménez Martínez M, Romero-Jarén R (2020) How resilient is the labour market against natural disaster? evaluating the effects from the 2010 earthquake in Chile. Nat Hazards 104:1481-1533. https://doi.org/10.1007/s11069-020-04229-9

JMA (2018) Report on the 2016 Kumamoto Earthquake. The Japan Meteorological Agency. https://www. jma.go.jp/jma/kishou/books/gizyutu/135/ALL.pdf

Kawasaki Y, Kuwahara M, Hara Y et al (2017) Investigation of traffic and evacuation aspects at Kumamoto earthquake and the future issues. J Disaster Res 12:272-286. https://doi.org/10.20965/jdr.2017.p0272

Kiyono J, Mabuchi R, Iwahashi T (2017) Behavior of vehicles during an earthquake focusing on brake operation. Proj Rep Tono Res Inst Earthq Sci 41:59-68.

Kurita N (2019) Association of the Great East Japan Earthquake and the Daiichi Nuclear Disaster in Fukushima City, Japan with birth rates. JAMA Netw Open 2:e187455. https://doi.org/10.1001/jamanetwor kopen.2018.7455

Kurozumi E, Tuvaandorj P (2011) Model selection criteria in multivariate models with multiple structural changes. J Econom 164:218-238. https://doi.org/10.1016/j.jeconom.2011.04.003

Lavrenz SM, Vlahogianni EI, Gkritza K, Ke Y (2018) Time series modeling in traffic safety research. Accid Anal Prev 117:368-380. https://doi.org/10.1016/j.aap.2017.11.030

Liboschik T, Fokianos K, Fried R (2017) tscount : an R package for analysis of count time series following generalized linear models. J Stat Softw. https://doi.org/10.18637/jss.v082.i05 
Liu C, Lu C, Wang S et al (2019) A longitudinal analysis of the effectiveness of California's ban on cellphone use while driving. Transp Res Part A Policy Pract 124:456-467. https://doi.org/10.1016/j.tra. 2019.04.016

Lopez Bernal J, Cummins S, Gasparrini A et al (2017) Interrupted time series regression for the evaluation of public health interventions: a tutorial. Int J Epidemiol 46:348-355. https://doi.org/10.1093/ije/ dyw098

Lopez Bernal J, Soumerai S, Gasparrini A (2018) A methodological framework for model selection in interrupted time series studies. J Clin Epidemiol 103:82-91. https://doi.org/10.1016/j.jclinepi.2018.05.026

Matsumoto M, Nakamura T, Uno N, et al. (2018) An analysis of effects of behavioral norms cognition on the vehicle speed at the occurrence of an earthquake by driving simulator experiments. JSTE J Traffic Eng 4:A_18-A_25. https://doi.org/10.14954/jste.4.3_A_18

Matsushita N (2019) Analysis on the impact of restoration measures "Fukkouwari" to recovery process of tourism industry in the Kumamoto earthquake. J Japan Soc Civ Eng Ser D3 Infrastruct Plan Manag 75:1-10. https://doi.org/10.2208/jscejipm.75.1

Milojevic A, Armstrong B, Wilkinson P (2017) Mental health impacts of flooding: a controlled interrupted time series analysis of prescribing data in England. J Epidemiol Community Health 71:970973. https://doi.org/10.1136/jech-2017-208899

Nakagawa D, Kobayashi H (2006) A study on the measures to address traffic issues in the event of an earthquake disaster -lessons from the hanshin awaji earthquake-. J Japan Soc Civ Eng Ser D 62:187-206. https://doi.org/10.2208/jscejd.62.187

Naqvi NK, Quddus MA, Enoch MP (2020) Do higher fuel prices help reduce road traffic accidents? Accid Anal Prev 135:105353. https://doi.org/10.1016/j.aap.2019.105353

Nishi H, Hino K (2018) Classification of time series trend and seasonal variation of traffic accidents : analysis of vehicle to vehicle accidents in Kanagawa prefecture. Reports City Plan Inst Japan 17:237-242

Nishimura T, Kajitani Y, Tatano H (2012) Damage assessment in tourism caused by an earthquake disaster. J Japan Soc Civ Eng Ser D3 Infrastruct Plan Manag 68:I_267-I_276. https://doi.org/10.2208/ jscejipm.68.I_267

Pridemore WA, Trahan A, Chamlin MB (2009) No evidence of suicide increase following terrorist attacks in the United States: an Interrupted time-series analysis of September 11 and Oklahoma City. Suicide Life-Threatening Behav 39:659-670. https://doi.org/10.1521/suli.2009.39.6.659

Quddus MA (2008) Time series count data models: An empirical application to traffic accidents. Accid Anal Prev 40:1732-1741. https://doi.org/10.1016/j.aap.2008.06.011

Runkle JD, Zhang H, Karmaus W et al (2012) Prediction of unmet primary care needs for the medically vulnerable post-disaster: an interrupted time-series analysis of health system responses. Int J Environ Res Public Health 9:3384-3397. https://doi.org/10.3390/ijerph9103384

Soares S, Ferreira S, Couto A (2020) Drowsiness and distraction while driving: a study based on smartphone app data. J Saf Res 72:279-285. https://doi.org/10.1016/j.jsr.2019.12.024

Stecklov G, Goldstein JR (2004) Terror attacks influence driving behavior in Israel. Proc Natl Acad Sci U S A 101:14551-14556. https://doi.org/10.1073/pnas.0402483101

Steinbach R, Perkins C, Tompson L et al (2015) The effect of reduced street lighting on road casualties and crime in England and Wales: controlled interrupted time series analysis. J Epidemiol Community Health 69:1118-1124. https://doi.org/10.1136/jech-2015-206012

Su JC, Tran AGTT, Wirtz JG et al (2009) Driving under the influence (of stress). Psychol Sci 20:59-65. https://doi.org/10.1111/j.1467-9280.2008.02257.x

Taguchi K, Watanabe H, Maruyama T (2019a) Time series analysis of traffic accident increase after the 2016 Kumamoto earthquake. Proceedings of 60th Infrastructure Planning Conference, JSCE.

Taguchi K, Watanabe H, Maruyama T (2019b) Time series analysis of traffic accident to explore the effect of the 2016 Kumamoto earthquake. Proceedings of the 2019 international conference on climate change, disaster management and environmental sustainability, pp 827-832

Taniguchi E (1997) Lessons and future perspectives on road transportation planning by the Great Hanshin-Awaji Earthquake. JSCE Proc Hanshin-Awaji Earthq, pp 307-314

TMNRC (2016) Traffic risks and countermeasures during reconstruction. Tokio Marine \& Nichido Risk Consulting Co.Ltd. Frontiers in Risk Management, pp 1-10. http://www.tokiorisk.co.jp/risk_info/ up_file/201601192.pdf

Turner SL, Karahalios A, Forbes AB et al (2020) Design characteristics and statistical methods used in interrupted time series studies evaluating public health interventions: a review. J Clin Epidemiol 122:1-11. https://doi.org/10.1016/j.jclinepi.2020.02.006

Ueno S, Hino Y, Wada M, et al. (1997) Some issues of traffic management based on needs of car usage after the earthquake disaster. JSCE Proc Hanshin-Awaji Earthq pp 293-298 
Venables WN, Ripley BD (2002) Modern applied statistics with S, 4th edn. Springer, Berlin

Wada M, Hino Y, Ueno S, Miyori K (1997) Traffic management based on some issues concerned with traffic condition after the earthquake disaster. Pap Hanshin-Awaji Earthquake, JSCE Infrastruct Plan Comm 299-306

Worthington A, Valadkhani A (2004) Measuring the impact of natural disasters on capital markets: an empirical application using intervention analysis. Appl Econ 36:2177-2186. https://doi.org/10. $1080 / 0003684042000282489$

Yang C-H, Xirasagar S, Chung H-C et al (2005) Suicide trends following the Taiwan earthquake of 1999: empirical evidence and policy implications. Acta Psychiatr Scand 112:442-448. https://doi. org/10.1111/j.1600-0447.2005.00603.x

Yonson R, Noy I, Ivory VC, Bowie C (2020) Earthquake-induced transportation disruption and economic performance: the experience of Christchurch, New Zealand. J Transp Geogr 88:102823. https://doi. org/10.1016/j.jtrangeo.2020.102823

Zhang N, Song D, Zhang J et al (2019) The impact of the 2016 flood event in Anhui Province, China on infectious diarrhea disease: an interrupted time-series study. Environ Int 127:801-809. https://doi.org/ 10.1016/j.envint.2019.03.063

Zhao S, Wang K, Liu C, Jackson E (2019) Investigating the effects of monthly weather variations on Connecticut freeway crashes from 2011 to 2015. J Saf Res 71:153-162. https://doi.org/10.1016/j.jsr.2019. 09.011

Publisher's Note Springer Nature remains neutral with regard to jurisdictional claims in published maps and institutional affiliations. 